\title{
Information needs of family caregivers of dependent individuals
}

\author{
Pedro Nuno Neves ${ }^{1,2}$, Carlos Sequeira 3 , Lleixà-Fortuño Mar', Lia Sousa ${ }^{2,5}$, and Carme Ferre-Grau ${ }^{4}$
}

\begin{abstract}
The increase in the number of dependent individuals means that more and more families find themselves in the situation of caregivers, with all the consequences that performing this role entails. Based on this reality, we considered it to be completely relevant to systematize knowledge in this area. This study aimed to identify the information needs of the family caregiver-dependent individuals in the available scientific literature, having performed an integrative review of the literature. The main results and conclusions indicate that the information needs of family caregivers can be grouped into three main themes: 1) caregiver knowledge and skills, 2) potential resources for the caregiver and 3) caregiver coping strategies and well-being. The comprehensive nature of the integrative review as the chosen method allowed us to get a good understanding of the information needs of family caregivers of dependent individuals. The relevance of this study to clinical practice is that, although it is still necessary to expand and enhance the scope of research in this area, we consider this information essential for all health professionals seeking to provide effective support to family caregivers, as well as to serve as support for the development of intervention projects and health services.
\end{abstract}

Keywords: Information needs, Health literacy, Family caregivers, Dependent individuals.

'USF Horizonte, ULS Matosinhos, Matosinhos, Portugal

2Instituto de Ciências Biomédicas de Abel Salazar, University of Porto, Porto, Portugal

${ }^{3}$ CINTESIS, Faculty of Medicine, University of Porto, Porto, Portugal

${ }^{4}$ Nursing Department, University Rovira and Virgili, Tarragona Spain)

${ }^{5}$ Neurology Department, São João Hospital Center, Porto, Portugal
Citation: Neves et al. Information needs of family caregivers of dependent individuals. International Journal of Clinical Neurosciences and Mental Health 2017; 4:5

DOI: https://doi.org/10.21035/ijcnmh.2017.4.5

Received: 25 May 2017; Accepted: 09 Oct 2017; Published: 27 Oct 2017

Correspondence: Pedro Nuno Neves

Rua Costa Fontes 142, 4460-289 Senhora Hora, Portugal

E-mail address: pedroneves.horizonte@gmail.com

Opes 


\section{Introduction}

According to the World Health Organization [1], the world has an unprecedented reality where, in 2030, the number of elderly people will surpass the number of children for the first time since censuses have been taken.

The increase in the elderly population, who are bearers of chronic and disabling diseases, and the increased survival of people following critical health events, has the consequence of increasing the number of people who depend on others for their self-care. This scenario leads to more and more families finding themselves in the situation of caregivers, which, despite being an increasingly common situation, is a major challenge for family members exposed to a relationship of providing care [2-4].

According to the literature, care provided by family or informal caregivers, tough varying depending on the clinical severity and the type of family dependence, has consequences at the family, social, economic and professional levels [5].

Associated with this reality, it has been established that an adequate level of health literacy is associated with better health outcomes, as well as a more effective use of health services and resources. On the contrary, low health literacy is typically associated with a higher number of hospitalizations, poor adherence to treatments [6] and a significant percentage of caregivers who present difficulties in following drug regimens or other tasks related to the care $[7,8]$.

Despite recent advances in Portugal, both at the research and policy levels, there is still much to investigate and understand. However, there are few programmes with validated educational content for family caregivers, and made available online with resources that respond to the real needs of caregivers. Their development is essential for family caregivers, but also for health institutions and health professionals.

This work seeks to identify and catalog the information needs which are shown most by family caregivers through research and analysis of the literature. This review is part of a broader project which intends to elaborate a family caregiver training program, in terms of literacy, for providing care.

\section{Materials and methods}

A literature review was conducted in order to identify the currently most advanced ways to transmit information that family caregivers need in order to exercise their role.

We considered that family caregivers are people who are centrally involved in providing and/or coordinating the care of dependent individuals, without financial compensation.

Information needs are understood as gaps in health literacy that caregivers need to see supplied with information, education and support.

Finally, a dependent individual is understood to be a person who, due to their clinical condition, age or disability, needs support and supervision in their self-care.
The literature review was guided by a set of well-defined criteria for data collection, analysis and presentation of results. We followed the following steps as the research protocol $[9,10]: 1)$ issue identification and selection of the hypothesis or research question for the preparation of the review; 2) establishment of criteria for inclusion and exclusion of studies/sampling or literature search;3) definition of the information to be extracted from selected studies/ characterization of the studies; 4) evaluation of the studies included in the review, 5) interpretation of results; 6) presentation of the review/knowledge synthesis.

Two reviewers, with experience in these themes, selected studies independently and the disagreements were resolved by consensus in a meeting specifically scheduled for this purpose.

To identify the categories of information, an analysis of the content of the results of the studies integrated in this review was conducted.

Research question: What are the information needs of family caregivers of dependent individuals?

From this research question, the following search descriptors were established: "family caregiver", "informal caregiver", "information needs", "health literacy needs", "information seeking", "dependent", "frail elderly" and Boolean characters "and " and "or " were used to combine the different descriptors.

A bibliographic search was carried out between November and December 2014, using English as the language of choice, in the following databases: EBSCO (Cinahl Plus with Full Text, Medline with full text, Psychology and Behavioral Sciences Collection and Educational Resource Information Center), Pubmed, Academic Search Complete and Scielo.

The following inclusion/exclusion criteria were established: works on family caregivers of adult/elderly dependents, excluding family caregivers of minors. Articles available in indexed, peer-reviewed databases, published between the years 2004 and 2014, with free access and full text were included. Duplicate articles were eliminated.

\section{Studies included in the literature review}

We obtained 857 articles distributed as follows, by database: 44 from Cinahl plus with full text; 76 from Medline with full text; 26 from Psychology and Behavioral Sciences Collection; 12 from Educational Resource Information Center; 443 from Pubmed; 164 from Academic Search Complete; and 92 from Scielo.

Of the 857 articles, 599 were excluded after reading the title, 201 articles were excluded after reading the abstract and an additional 6 articles were excluded due to lack of access to the full article.

Fifty-one articles were included for full-text analysis, 11 of which were chosen for the integrative review through consensus by the two reviewers. 
The analysis of 11 articles included in this integrative review (Table 1), performed by the main author of the article, showed that they were obtained from ten countries: the UK, Japan, Northern Ireland, Canada, Australia, the Netherlands, Italy, New Zealand, Portugal and Iran, and their publication years varied between 2004 and 2014 .

There were various clinical situations that caused some kind of dependence which were analyzed in the studies, from elderly people with dementia, epilepsy, heart failure and brain damage to cancer at an advanced stage.

Of these 11 articles, two were literature reviews on the needs of caregivers that were included after their analysis to reveal that even though they had a different focus from this review, they added relevant information to our work.

\section{Results}

After analyzing the 11 articles, three dimensions emerged. The first dimension is related to the knowledge and skills to perform the role of caregiver. A second dimension related to external resources provided by the community or health services, among others. And a third dimension related to the internal resources of the caregiver himself to meet the demands of the role he plays.

\section{Caregiver knowledge and skills}

This dimension cuts across all studies. Caregivers need to get information about their family member's illness [12-21].

Many caregivers consider that they have knowledge about a particular disease or dependent condition, but demonstrate the same need to validate it with a professional, that is, to obtain information from what is considered a reliable source [13-15, 20].

Information on the disease and its clinical implications can be transmitted by the professional who makes the diagnosis, as well as by professionals who provide the socalled community support [13, 20,21].

Knowledge of the symptoms $[14,16,19,20]$ that may be present in a certain disease is also a focal point that was mentioned by the caregivers in the studies analyzed, especially when the disease has a large diversity of symptoms that need to be recognized and controlled $[11,14,15,19]$.

Information needs also are found with the anticipation of care $[11,14,15,19]$, i.e. what the prognosis and the progress of the health status of their family member is. This knowledge also has implications for the caregiver himself because it is this knowledge about the evolution and prognosis of the disease or their family member's dependent condition that allows caregivers to program the care in their daily lives [16] and acquire support for the care $[13,15,18]$.

The proper time for receiving or soliciting information and the availability that professionals should show to transmit it is also covered. Caregivers report that the professionals are not always available when they are needed $[14,20]$ or, being present, they are not able to maintain adequate monitoring $[14,15,16,21]$.
In addition to knowledge, caregivers feel the need for training to develop skills to perform the role of a care provider $[11,13,16,18]$, since they do not always feel able to provide all of the necessary care.

The amount of time they have played the role of caregiver, despite helping with the feeling of being able to provide quality care, does not prevent other needs from arising due to clinical changes in their family $[13,16]$.

The way in which these skills can be learned or trained requires a prior needs assessment by professionals [20], so that psycho-educational programs or other measures within the scope of providing information or learning are appropriate for caregivers $[11,12,16,18,21]$.

\section{Potential caregiver resources}

The caregivers' information needs are also felt at the level of potential resources for the caregiver. Knowing what social and community resources are available for their particular case [17], such as back office services, public, private and social support institutions, patient organizations or teams of professionals to assist with care at the patient's home $[13,17,20]$.

Most studies in this review report that the caregiver demonstrates the need to obtain care for their family members, or at least consultation and supervision in regards to the care they provide, from health professionals with specific expertise in the type of care required by the clinical situation $[12,13,15-17,20,21]$.

Information regarding financial support $[13,17,21]$ is also a concern of the family caregivers. Effectively providing quality care and use of necessary technical aids, such as diapers, is necessary and costly. Added to this fact, the vast majority of family caregivers do not work because they are abdicated to provide care to their family member or they are retired $[17,21]$.

The existence of specific programs or interventions for caregiver training for performing the role of a care provider is described in several studies $[16,18,19,21]$ as a need felt by the caregiver.

There are a variety of clinical conditions that can lead to some kind of dependence in a person's self-care. Thus, caregivers feel the need to be trained to perform various tasks, from changing a diaper to controlling symptoms through using medication.

This situation leads them to stress the need for such support caregiver programs to be available in the form of educational programs that can be more generic in content and in the recipients since certain situations and contexts are common to many caregivers, but also specifically directed to each of the caregivers according to their specific needs and preferences $[11,18,21]$.

Above all, professionals are expected to recognize the diversity of learning styles, the specific needs of each caregiver and that such information be accessible at times, locations and in forms of information transmission that suits the caregivers $[13 ; 21]$. 
Table 1. Articles included in this integrative review.

Title of the article
Author (s), country and
year of publication

"The information needs of carers of adults diagnosed with epilepsy"

Kendall, S. et al.

United Kingdom, 2004

"Information needs and the related variables of Japanese family caregivers of terminally ill cancer patients"

Fukui, S.

Japan, 2004

"Dementia and challenging behavior: the needs of family caregivers"

Scott, A. Et al.

Northern Ireland, 2005

"Assessment of family needs Following acquired brain injury in Saskatchewan"

Murray, H., Maslany, G., Jeffery $B$.

Canada, 2006

"Service and support needs of Australian carers supporting the family with disability at home"

Burton-Smith, R. et al.

Australia, 2009

"Informal caregivers of persons with dementia, their use and needs for specific professional support: a survey of the National Dementia Programme;

Peeters, J. et al.

Netherlands, 2010

"Burden and needs of 487 caregivers of patients in vegetative state and in minimally conscious state: Results from a national study "

Leonardi, A. et al.

Italy, 2012

"Essential knowledge for family caregivers: a qualitative study"

Angelo, J., Egan, A., Reid, K. New Zealand, 2013

"The needs of informal caregivers of elderly people living at home: an integrative review"

Silva, A. et al.

Portugal, 2013

\section{Objective}

Explore the infor-

mation needs of

caregivers and how

the information from

the professionals

can become more

effective;

To identify the

information needs

of family caregivers

of Japanese patients

who are terminally ill

with cancer;

Identify the needs

of family caregivers

of patients with de-

mentia, particularly

to deal with their

behavior;

Explore the needs of the family and to what extent these needs are being or can be met;

Understand what the needs of caregivers of family members with addiction in their homes are;

Understand what the uses, support needs and professional information are for informal caregivers of people with dementia;

Understand the main needs and the level of wear on caregivers of patients in a vegetative state or minimal state of consciousness;

Identify what information the palliative care teams routinely provide to family caregivers;

Literature review on the knowledge of informal caregivers.

\section{Methodology and Sample}

Mixed Method Interview with 12 caregivers who provided the basis for the preparing a questionnaire applied to 70 other caregivers;

Qualitative method us ing the an interview of 66 caregivers

Qualitative method us ing the "Focus-Group" technique with seven caregivers.

Exploratory and descriptive study using a questionnaire called the "Family Needs Questionnaire (FNQ)", applied to 66 caregivers;

Mixed methods, with 448 caregivers who responded to a questionnaire and open-ended questions;

Quantitative method using an exploratory and descriptive study, by applying the

"National Dementia

Programme Questionnaire" to 984 caregivers between 2006 and 2007;

Quantitative method using a multi-center observational study. 487 participants were assessed using various tests;

Qualitative method using the Nominal Group Technique (a type of Focus Group) with 17 health professionals in community palliative care;

Qualitative method: integrative literature review;

\section{Key Findings / Conclusions}

- Need to improve knowledge and levels of information - Professionals are not able to properly accompany this process;

- They indicate needing other sources of information, not just leaflets;

- Reliable needs information on the disease and its evolution;

- Being informed is a prerequisite for more effective coping and fewer cases of anxiety and stress for care providers;

- Unpreparedness of the family to provide care;

- Coping strategies, support network and nursing staff for home care are reported needs;

- Information on the symptoms and progression of the disease;

- Importance of having innovative methods to support the caregiver, such as videos;

- Information on the health status and disease progression;

emotional support;

- Caregivers report that many needs are not perceived by the professionals that could be addressed by the existence of specific support programs and caregiver support;

The main needs are the level of information about the health of their family members; the services and resources available;

- Need for support to prevent situations of exhaustion related to the care;

- The existence of specific support programs on "becoming" a caregiver

Caregivers report that additional information is needed on the course of the disease; and on the control and evolution of the most difficult symptoms, such as confusion;

- Support for the development of effective coping strategies;

- Information on health and social resources available

Over $75 \%$ of the participants reported six needs for information and communication that the authors have cataloged: 1) information from health care professionals regarding the disease and prognosis, 2) the need to cooperate and participate in decisions, 3 ) the need to satisfactorily communicate with all health team professionals, 4 ) the need to be able to easily contact the healthcare professionals, 5) the need to know what problems may eventually arise in the course of the disease and 6) be trained to perform all tasks related to the care;

The three main categories of needs:

- Taking Care of oneself (maintaining activities and interests, what support can be used from the institutions);

- Learn practical skills (control and recognition of symptoms; proper use of medical equipment and technical aids);

- Knowing what to expect (report that care is a continuous act; anticipation care needs);

The needs are grouped into 4 groups: 1) information and communication, 2) professional support, 3) effective communication and 4) legal and financial support; Many gaps were also found in the studies on these subjects; 
Table 1. Articles included in this integrative review. (cont.)

\begin{tabular}{|c|c|c|c|}
\hline $\begin{array}{l}\text { Title of the article } \\
\text { Author (s), country and } \\
\text { year of publication }\end{array}$ & Objective & $\begin{array}{l}\text { Methodology and } \\
\text { Sample }\end{array}$ & Key Findings / Conclusions \\
\hline $\begin{array}{l}\text { "Needs of informal caregiv- } \\
\text { ers for the care of a depen- } \\
\text { dent individual: an integra- } \\
\text { tive literature review" } \\
\text { Melo, R.; Rua, M. and Santos, } \\
\text { C. } \\
\text { Portugal, } 2014\end{array}$ & $\begin{array}{l}\text { Conduct a literature } \\
\text { review of the needs } \\
\text { of informal caregivers } \\
\text { caring for dependent } \\
\text { individuals; }\end{array}$ & $\begin{array}{l}\text { Qualitative method } \\
\text { using an Integrative } \\
\text { Literature Review. } \\
21 \text { articles were } \\
\text { analyzed; }\end{array}$ & $\begin{array}{l}\text { The authors grouped the needs found in the literature } \\
\text { according to the Meleis Transitions Theory: a) community } \\
\text { and social resources, b) knowledge and preparation, c) } \\
\text { personal meaning, beliefs and attitudes, d) socio-economic } \\
\text { condition; } \\
\text { The correct diagnosis of needs allows for proper planning } \\
\text { and greater health gains for the caregiver and the depen- } \\
\text { dent individual; }\end{array}$ \\
\hline $\begin{array}{l}\text { "Informational needs and } \\
\text { related problems of family } \\
\text { caregivers of heart failure } \\
\text { patients: A qualitative study" } \\
\text { Bahrami, M. et al. } \\
\text { Iran, } 2014\end{array}$ & $\begin{array}{l}\text { To explore the needs } \\
\text { of family caregivers } \\
\text { of patients with heart } \\
\text { failures; }\end{array}$ & $\begin{array}{l}\text { Qualitative study } \\
\text { using the interviews } \\
\text { of } 19 \text { caregivers; }\end{array}$ & $\begin{array}{l}\text { Four major needs arose: 1) lack of knowledge to provide } \\
\text { care, 2) inaccessibility to safe sources of information, } 3 \text { ) } \\
\text { lack of guidance from health teams and 4) ambiguity of } \\
\text { feelings related to care due to the unpredictable nature of } \\
\text { the disease; } \\
\text { Health professionals should develop educational programs } \\
\text { and effective support for caregivers; }\end{array}$ \\
\hline
\end{tabular}

Since the act of providing care is very demanding, including in terms of time required for the care, it is often difficult for informal caregivers to find answers to their needs at normal times and places, so new approaches that are more innovative and flexible are desirable $[12,17,20]$.

\section{Coping strategies and caregiver well-being}

Receiving support and information on how to develop effective coping strategies $[14,18,19]$ are information needs identified by caregivers.

The care process, usually long and exhausting, is conducive to the development of ambivalent feelings [20], because the care takes time away from other tasks, such as accompanying other family members [21].

Information needs on how to recognize the signs of exhaustion, depression and distress $[13,16]$, inherent to the act of caring, as stated earlier, is always a demanding and exhausting challenge [19].

Caregivers also expressed the desire to see their beliefs and attitudes [17] recognized by health professionals when they are provided with emotional support [18].

\section{Discussion and implications for clinical practice}

Despite the large number of articles focused on the informal caregivers, few are targeted exclusively toward the informational needs of caregivers who care for relatives with a clinical condition that results in dependency.

The choice of the qualitative methodology in most studies prevents further analysis, such as meta-analysis. In this study, we have chosen to exclude data not obtained by means of researching the databases, as well as articles that did not have at least a summary in English and did not underwent peer-review, which may have taken away some interesting information for analysis. However, we considered that by using an integrative literature review, carried out accurately and with transparency in the research methodology, we can contribute useful knowledge about the information needs of family caregivers of dependent individuals.
The studies analyzed here cover a variety of countries, which helps us to have a more global and comprehensive view of the phenomenon, although it impedes comparisons between studies.

The need for information in terms of skill levels, abilities and knowledge is a cross-cutting issue for all studies, demonstrating its importance for caregivers, and these data should be at health professionals' center of attention.

Knowledge of the needs can help institutions and professionals tailor their approach to the caregiver and develop information, education and support strategies, thus making these interventions more effective, with expected gains for caregivers and dependent individuals, as well as for healthcare systems in general.

\section{Conclusions}

The recognition of the information needs of family caregivers of dependent individuals constitutes the first step to be undertaken by professionals before planning any intervention directed at caregivers.

From the analysis of these 11 articles, three dimensions emerged with regards to the information needs of caregivers of dependent individuals: 1) caregiver skills, abilities and knowledge, 2) potential resources for the caregiver, 3 ) caregiver well-being.

The literature review revealed the existence of a shortage of quality studies on this topic, because most studies have a small sample, so it would be important to conduct more studies on this subject.

As future challenges, we consider the broadening and deepening of research in this area so that by increasing and deepening the knowledge available, interventions among family caregivers may become more effective.

\section{Competing interests}

The author declares no conflict of interest. 


\section{References}

1. WHO. Global Health and Aging. 2011.

2. LaVela SL, Ather N. Psychological health in older adult spousal caregivers of older adults. Chronic Illness 2010; 6:67-80. https://doi.org/10.1177/1742395309356943

3. Sequeira C. Cuidar de idosos Com dependência Fisica e Mental. Lisboa: Lidel, Edições Técnicas Lda, 2010.

4. Zabalegui $\mathrm{A}$ et al. Recursos y consecuencias de cuidar a las personas mayores de 65 anos: una revisión sistemática. Gerokomos 2004; 15(4):13-22.

5. Sequeira C. Difficulties, coping strategies, satisfaction and burden in informal Portuguese caregivers. Journal of Clinical Nursing 2013; 22(3-4):491-500. https://doi.org/10.1111/jocn.12108

6. Berkman $\mathrm{N}$ et al. Low health literacy and health outcomes: an updated systematic review. Ann Intern Med 2011; 155:97-107. https://doi.org/10.7326/0003-4819-155-2-201107190-00005

7. Lindquist, Lee, et al., et al. Inadequate Health Literacy Among Paid Caregivers of Seniors. J Gen Intern Med 2011; 26(5):474-479. https://doi.org/10.1007/s11606-010-1596-2

8. Sotto Mayor M, Sequeira C, García B. Consulta de enfermaria dirigida a cuidadores informales: instrumentos de diagnóstico e intervención. Gerokomos 2013; 24(3):115-119. https://doi.org/10.4321/S1134-928X2013000300004

9. Mendes K, Silveira R, Galvão C. Integrative Review: Método de pesquisa para a incorporação de evidências na saúde e na enfermagem. Texto Contexto Enfermagem 2008; 17(4): 758-764. https://doi.org/10.1590/S0104-07072008000400018

10. Beyea S, Nicoll LH. Writing an integrative review. AORN J. 1998; 67(4):877-880 https://doi.org/10.1016/S0001-2092(06)62653-7

11. Angelo JK, Egan R, Reid K. Essential knowledge for family caregivers: a qualitative study. International Journal of Palliative Nursing 2013; 19(8):383-388.

https://doi.org/10.12968/ijpn.2013.19.8.383

12. Bahrami M et al. Informational needs and related problems of family caregivers of heart failure patients: A qualitative study. Journal of Education and Health Promotion 2014; 3:113. https://doi.org/10.4103/2277-9531.145908
13. Burton-Smith R et al. Service and support needs of Australian carers supporting a family member with disability at home. Journal of Intellectual and Developmental Disability 2009; 34(3):239-247. https://doi.org/10.1080/13668250903103668

14. Fukui S. Information needs and the related variables of Japanese family caregivers of terminally ill cancer patients. Nursing and Health Sciences 2004; 6:29-36. https://doi.org/10.1111/j.1442-2018.2003.00170.x

15. Kendall S, Thompson D, Couldridge L. The information needs of carers of adults diagnosed with epilepsy. Seizure 2004; 13:499-508. https://doi.org/10.1016/j.seizure.2003.12.003

16. Leonardi $\mathrm{M}$ et al. Burden and needs of 487 caregivers of patients in vegetative state and in minimally conscious state: Results from a national study. Brain Injury 2012; 26(10):1201-1210. https://doi.org/10.3109/02699052.2012.667589

17. Melo RMC, Rua MS, Santos CS. Necessidades do cuidador familiar no cuidado à pessoa dependente: uma revisão integrativa da literatura. Revista Enfermagem Referência 2014; IV(2):143-151. https://doi.org/10.12707/RIV14003

18. Murray HM, Maslany GW, Jeffery B. Assessment of family needs Following acquired brain injury in Saskatchewan. Brain Injury 2006; 20(6):575-585. https://doi.org/10.1080/02699050600664590

19. Peeters J et al. Informal caregivers of person with dementia, their use and needs for specific professional support: a survey of the National Dementia Programme. BMC Nursing 2010; 9:9. https://doi.org/10.1186/1472-6955-9-9

20. Scott AL, Deirdre and Loughlin N. Dementia and challenging behavior: the needs of family caregivers. Nursing older people 2005; $17: 1$

21. Silva AL et al. The needs of informal caregivers of elderly people living at home: an integrative review. Scandinavian Journal of Caring Sciences 2013; 27:792-803. https://doi.org/10.1111/scs.12019

22. Petronis A. The origin of schizophrenia: genetic thesis, epigenetic antithesis, and resolving synthesis. Biol Psychiatry 2004; 15;55(10):965-70. 